\title{
Housing challenges in shrinking and aging Japanese cities
}

\author{
Tomoko Kubo ${ }^{\text {a }}$ \\ ${ }^{a}$ Faculty of Life and Environmental Sciences University of Tsukuba, tmkkb@geoenv.tsukuba.ac.jp
}

Keywords: Shrinking city, aging, housing, policy implications, Japanese cities

\begin{abstract}
The topic of shrinking cities has been one of the most important urban issues in the past three decades. Couch and Cocks (2013) reviewed studies on the outcomes of recent shrinking cities: (1) rapid out-migration from post-socialist countries such as the movement from East Germany to West Germany in the 1990s; (2) economic -decline as an additional trigger for out-migration such as in old industrial areas in Northern England and the Rust Belt of the United States; and (3) rapid demographic changes such as low fertility and longevity-led ageing of the society leading to shrinking regions in the European countries and Japan. Although many studies have been conducted in East Germany, the old industrial cities, and the aging European countries (Nordvik and Gulbrabdsen 2009, Hoekstra et al. 2018, Hollander 2018), little is known about shrinkage in Japanese cities. Over recent decades, the debates on shrinking cities have been widely studied; these studies can be classified into three categories: (1) studies to understand the background reasons that caused shrinkage, (2) those to analyze the effects or outcomes of shrinkage (e.g., increase in housing vacancies or vacant lots, growth of crime rate or political challenges), and (3) those to propose policy implications or practical solution strategies to overcome shrinkage (Hollander and Nemeth 2011).
\end{abstract}

First, Hollander (2018) and other studies identified the relationship between the neighborhood life cycle (Hoover and Vernon 1959, or studies by the Chicago schools) and urban shrinkage, with regards to old industrial cities such as those in the Rust Belt of the United States and erstwhile mining towns in North England. Hoover and Vernon (1959) proposed that a neighborhood follows a five-stage cycle, comprising the stages of development, transition, downgrading, shrinkage, and renewal; this five-stage model is linked to the discriminative housing policies from the 1930s until the 1970s in the United States (Metzger 2000). In addition to these neighborhood cycles, other factors such as economic decline, outmigration and population loss, demographic changes (Nordvik and Gulbrabdsen 2009, Couch and Cocks 2013), social transition, globalization and neo-liberalization have transformed housing, welfare, and family relations in many countries (Yui et al. 2017, Ronald and Lennarts 2018). In East Germany, housing oversupply during the post-socialist shrinking periods acted as a catalyst to form a new residential segregation pattern in Leipzig (Grobmann et al. 2015). Some neighborhood conditions can lead to an increase in the number of housing abandonments or long-term housing vacancies in specific neighborhoods, as demonstrated by various studies mentioning oversupply of housing during the housing bubble periods and longitude low demand neighborhoods in the United States (Molloy 2016), the high ratio of poverty (Immergluck 2016), and the conditions of the surrounding neighborhoods (Morckel 2014). Second, the population loss caused by massive out-migration and a rise in housing abandonment or housing vacancies were the most common outcomes of urban shrinkage. Out-migration was triggered by the movement to seek better job opportunities or quality of life, urban life cycles with growth and decline (Couch and Cocks 2013), and the longitudinal decline process of population (Alves et al. 2016). Nordvik and Gulbrandsen (2009) analyzed aging-led shrinkage with a case study in Norway and found a spatial characteristic of shrinkage that occurs more often in suburbs than in city-centers, and the positive relation between the rise in the vacant property ratio and an increase in the elderly population in a region. The out-migration of the younger generation, arising from the desire to move away from parental homes in suburbs, and the deaths among the parental generation that have occurred in the last 30 to 50 years have led to a gradual increase in vacant housing in the suburb in Norway (Nordvik and Gulbrabdsen 2009). Apparently, the Japanese suburban neighborhoods have experienced the rise in housing vacancies and ageing population through the similar mechanism with that in Norway, but the reality and spatial patterns of shrinking-related problems vary reflecting the urban and housing policies, housing market characteristics, and embedded relationship between housing and family in society. According to Couch and Cocks (2013), the rise in housing vacancies in a region arises due to several factors, as follows. The first factor is that of shortterm vacancies for which there is no demand in the local housing market; this issue can be resolved through public intervention in terms of reinvestment in inner-city social housing, such as in the United Kingdom in the 1980s. The second factor is that of oversupply of housing as compared to the housing demand in a region; this is caused by lower satisfaction among residents in their residential environment or inequality in public investment and access to private financial resources by local residents. Moreover, shrinking cities with a high ratio of long-term housing vacancies tend to experience an increase in crime such as burglary. This is because the rise in housing vacancies causes a decline in neighbourhood vitality required to protect social disorder; vacant housing is used to store stolen goods or sell drugs, and there is a "broken window effect" with regard to abandoned housing vacancies (Jones and Pridemore 2016).

There have recently been more meaningful discussions on how to handle the problems of shrinking cities. As Hoekstra et al. (2018) mentioned, there have been two main approaches in these discussions: one approach has focused on increasing the population in shrinking cities again, whereas, the other accepts longitudinal shrinkage patterns and aims to 
increase the quality of life of present and future residents (Hollander and Nemeth 2011). The former approach advocates entrepreneurial policies to attract new residents, resulting in an increase in inequality within a region, unsold housing, and a lack of affordable housing (Hoekstra et al. 2018). The latter approach employs methodologies such as selective demolition of abandoned housing to control the housing stock of a region, promoting down-sizing or right-sizing to meet the changes in the housing demands of residents, or densification of urban buildings to recreate walkable neighborhoods (Hoekstra et al. 2018). Hollander and Nemeth (2011) proposed smart decline strategies based on the concept of social justice, with an emphasis on the following aspects: accepting voices from diverse actors, utilizing different types of technology to share information about citizens to problematize uneven power structure, transparent decision-making processes with clear evaluation, and paying attention to the scale of decision making (e.g., the total planning burden is shared among regional levels, and the required interventions are conducted at local levels). Compared to the rich accumulation of literature on shrinking cities in Western countries, the Japanese situation has not been discussed sufficiently and there is an absence of strategies to resolve the issues in Japan. Research on shrinkage and housing has clarified that factors related to housing, welfare, and family relations are embedded in the social fabric, and the relationships vary by region or by country (Ronald and Lennerts 2018). Therefore, it is necessary to obtain deeper understanding of the housing challenges in shrinking and aging Japanese cities. The present study aims to review the above-mentioned three categories of shrinking city debates in Japan, to propose practical countermeasures for shrinking and aging Japanese cities. First, we review the reasons that caused the shrinkage in Japanese cities. Second, we analyze the increase in housing vacancies as an outcome of this shrinkage. Third, we examine the political countermeasures that have been adopted in Japan and evaluate their efficacy in the Japanese situation. Finally, through these analyses, we propose policy implications to deal with the problems of aging and shrinking cities in Japan. The major findings of the study are as follows: First of all, existing systems that had been established during the economic and urban growth periods of Japan are not suitable to address the new demands of the shrinking and aging era. Therefore, a great divide in terms of residential environments has occurred within a metropolitan area or between cities. Lesser access to financial resources to reinvest in old suburban neighborhoods or local cities accelerates the divide or inequality in terms of residential environments. Second, an increase in housing vacancies can decrease the quality of life of older adults in these shrinking neighborhoods. Third, these problems could be resolved by adopting a strategy of smart decline, with selective investment to control housing stock, and by accepting aging in place in shrinking neighborhoods. We discuss the challenges in implementing these possible solutions in Japanese cities.

\section{References:}

Alves, D., Barreria, A.P., Guimaraes, M.H., and Panagopoulos, T. (2016) Historical trajectories of currently shrinking Portgues cities: a typology of urban shrinkage. Cities 52, 20-29.

Couch, C. and Cocks, M. (2013) Housing vacancy and shrinking city: trends and policies in the UK and the city of Liverpool. Housing Studies 28(3), 499-519.

Grobmann, K., Arndt, T., Hasse, A., Rink, D. and Steinfuhrer, A. (2015) The influence of housing oversupply on residential segregation: exploring the post-socialist city of Leipzig. Urban Geography 36(4), 550-577.

Hoekstra, M.S., Hochstenbach, C., Bontje, M.A., and Musterd, S. (2018) Shrinkage and housing inequality: policy responses to population decline and class change. Journal of Urban Affairs (https://doi.org/10.1080/07352166.2018.1457407)

Hollander, J. B. and Nemeth, J. (2011). The bounds of smart decline: a foundational theory for planning shrinking cities. Housing Policy Debate, 21(3), 3-367.

Hollander, J.B. (2018) A research agenda for shrinking cities (Elgar research agendas). Edward Elgar Publisher.

Hoover, E. M. and Vernon, R. (1959). Anatomy of a metropolis. Harvard University Press.

Immergluck, D. (2016) Examining changes in long-term neighbourhood housing vacancy during the 2011 to 2014 U.S. National recovery. Journal of Urban Affairs 38(5), 607-622.

Jones, R.W., and Pridemore, W. A. (2016) A longitudinal study of the impact of home vacancy on robbery and burglary rates suring the U.S. housing crisis, 2005-2009. Crime \& Delinquency 62(9), 1159-1179.

Metzger, J. T. (2000) Planned abandonment: the neighborhood life-cycle theory and national urban policy. Housing Policy Debate 11 (1), 7-40.

Morckel, V.C. (2014) Spatial characteristics of housing abandonment. Applied Geography 48, 8-16.

Nordvik, V. and Gulbradsen, L. (2009) Regional patterns in vacancies, exits and rental housing. European Urban and Regional Studies 16(4), 397-408.

Ronald, R. and Lennarts, C. (2018). Housing careers, intergenerational support and family relations. Housing Studies, 33(2), 147-159.

Yui, Y., Kubo, T., and Miyazawa, H. (2017) Shrinking and super-aging suburbs in Japanese metropolis. Sociology Study 7(4), 195-204. 